as duodenal ulcer is associated with stress, the disease would be highly prevalent among them. The facts are contrary to expectation: thus on the one hand Geddes ${ }^{9}$ reports only two cases in five years among 18622 black migrant mineworkers admitted to hospital, while our findings show that the main sufferers from duodenal ulcer are the younger, urbanised, educated men in the higher employment categories.

A possible explanation for both our observations and those of Susser in Britain is that where the need to make considerable adjustments is shared by a large proportion of a population stress may be reduced and adaptation facilitated. As certain individuals gain in skill and proficiency and exhibit certain talents and characteristics, however, they become upwardly mobile. Not only do they find themselves with greater responsibilities on the job, but they must also adjust to other aspects of their new roles. Those who cannot cope with these new stresses cannot, however, find comfort with the mass of their fellows since they have moved upwards out of their ranks. This might explain why Dunn and $\mathrm{Cobb}^{10}$ found a high rate of peptic ulcer among foremen, and why the blacks in our sample were clearly upwardly mobile into the higher ranks of the working class.

In conclusion, we must emphasise that our study was no more than a preliminary exploration of a field in which sophisticated and reliable epidemiological research is sadly lacking and where assumptions are often groundless. The question of the relation between stress and duodenal ulcer remains a matter for considerable research, as does the question raised by Susser's data on why certain types of stress manifest themselves in duodenal ulcers while others do not.

The population figures for blacks in Johannesburg were derived $\underline{\underline{T}}$ from provisional unpublished results of the 1970 official population $>$ census, by courtesy of the Department of Statistics, Pretoria. We $\mathbb{D}$ thank Mr David White for providing the adapted Taylor anxiety scale and the preliminary results of his study among black miners, and the superintendent, Baragwanath Hospital, for permission to publish. Finally, we are indebted to the Stella and Paul Loewenstein Trust for a grant to the African Studies Institute.

\section{References}

Campbell, G D, Seedat, Y K, and Daynes, G, Clinical Medicine in $\overrightarrow{0}$ Africans in Southern Africa. Churchill Livingstone. Edinburgh and London, 1973.

2 Beyers, C F, Fournal of the Medical Association of South Africa, 1927, 1, 606

${ }^{3}$ Eagle, P C, and Gillman, J, South African fournal of Medical Science, $1938,3,1$.

${ }^{4}$ Bremner, C G, South African fournal of Surgery, 1971, 10, 139.

5 Taylor, J A, fournal of Abnormal and Social Psychology, 1953, 48, 285.

6 Department of Statistics, Population Census 1970 Report No 02-05-10, Government Printer. Pretoria, 1976.

7 Susser, M, and Stein, Z, Lancet, 1962, 1, 1115.

${ }^{8}$ Susser, M, Fournal of Chronic Diseases, 1967, 20, 435.

${ }^{9}$ Geddes, E W, personal communication, 1977.

, and Cobb, S, fournal of Occupational Medicine, 1962, 4, 343.

(Accepted 1 December 1977)

\title{
Coronary heart disease in relation to age, sex, and the menopause
}

\author{
R F HELLER, H S JACOBS
}

British Medical fournal, 1978, 1, 472-474

\section{Summary and conclusions}

Examination of the Registrar General's mortality data suggested that women do not lose protection from coronary heart disease (CHD) after the menopause. Apparently, at around the age of 50 men begin to lose a factor that had previously put them at increased risk of developing CHD compared with women. Male sex hormones may be risk factors for CHD, and further studies are needed to clarify their role in the aetiology of CHD in men.

\section{Introduction}

Men are more likely to develop coronary heart disease (CHD) than women. After the age of 50 the difference between men and women in the mortality rate from CHD diminishes until the age of 80 or more, when death rates from CHD are similar in both. ${ }^{1}$ Many have thought that young women are protected from CHD by ovarian hormones, and that they lose this protection after the

St Mary's Hospital Medical School, London W2 1PG R F HELLER, MD, MRCP, lecturer in medicine and epidemiology H S JACOBS, MD, MRCP, senior lecturer in obstetrics and gynaecology menopause, when concentrations of these hormones are reduced. If this were so the rate at which women die of $\mathrm{CHD}$ after the menopause would be accelerated. We have examined the differences between men and women in mortality from CHD to test the consistency with this and other hypotheses.

\section{Methods and results}

Figure 1 shows the death rates from CHD in men and women (coded as ischaemic heart disease, International Classification of Diseases (ICD) categories 410-414, by the Registrar General of England and N Wales) averaged over the most recent five years for which figures $N$ were available (1970-4). A semilogarithmic scale was used to compare the proportionate change from one age group to the next. When examining the relation between CHD death rates and age, single 0 straight lines were found not to fit the data well, but for both men and women there was a curvilinear relation (obtained by fitting a quadratic $\stackrel{\mathcal{P}}{\rightarrow}$ equation to the data). To examine any change in death rates at the 0 time of the menopause straight lines were fitted for age groups below 50 (the median age of the menopause in the $\mathrm{UK}^{2}$ ) and 50 and above. Two such lines appeared to fit the data as well as the single curve over the whole age span in both men and women. The slope of the line for women (fig 1) was a little less steep above 50 years than below, showing that there was no acceleration in the increase of CHD death rates after the menopause. Although in each age group the death rates were higher in men, below the age of 50 the rates of increase (that is, the slopes) were similar for both sexes. After the age of 50 the rate of increase in men was much lower than it was both in younger groups of men and in women. Apparently a change occurred around the time of the menopause, but it was in men rather than women.

Figure 2 shows that this difference between men and women clearly 


\section{BRITISH MEDICAL JOURNAL 25 FEBRUARY 1978}

emerges at around the age of 50 . In the younger groups there was a threefold to fourfold increase in death rate between succeeding age groups, but later on the difference diminished to less than double. Young men and women were similar in this respect, but from the interval between the 45-49 and 50-54 age groups a significant difference between men and women emerged: mortality increased less between successive age groups in men than in women. This supports the findings in fig 1 , and shows that men and women develop similar

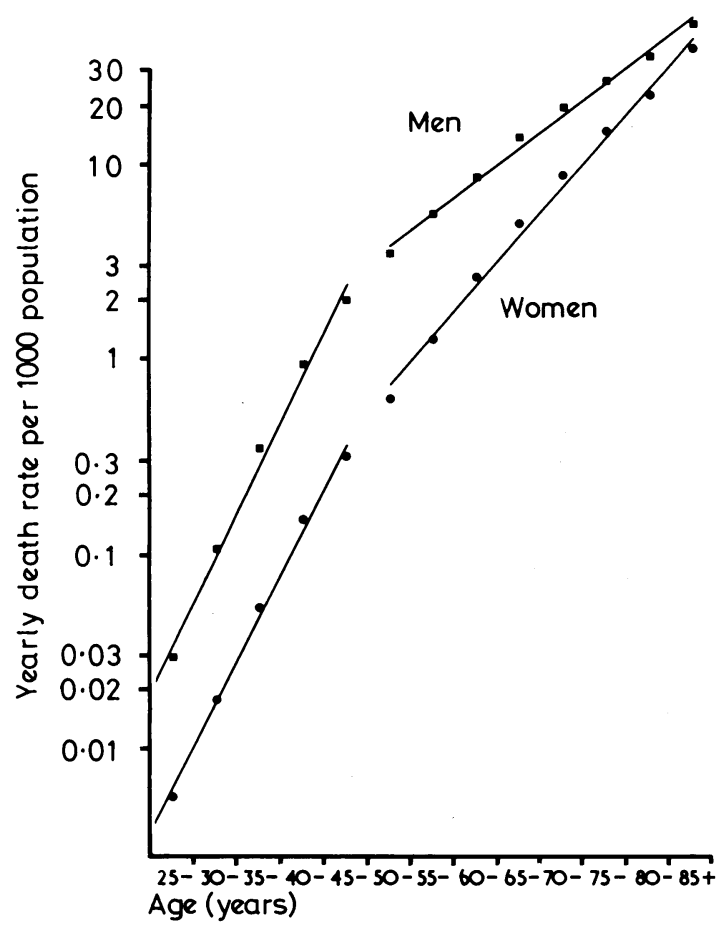

FIG 1-Death rates from ischaemic heart disease in men and women according to age (England and Wales 1970-4).

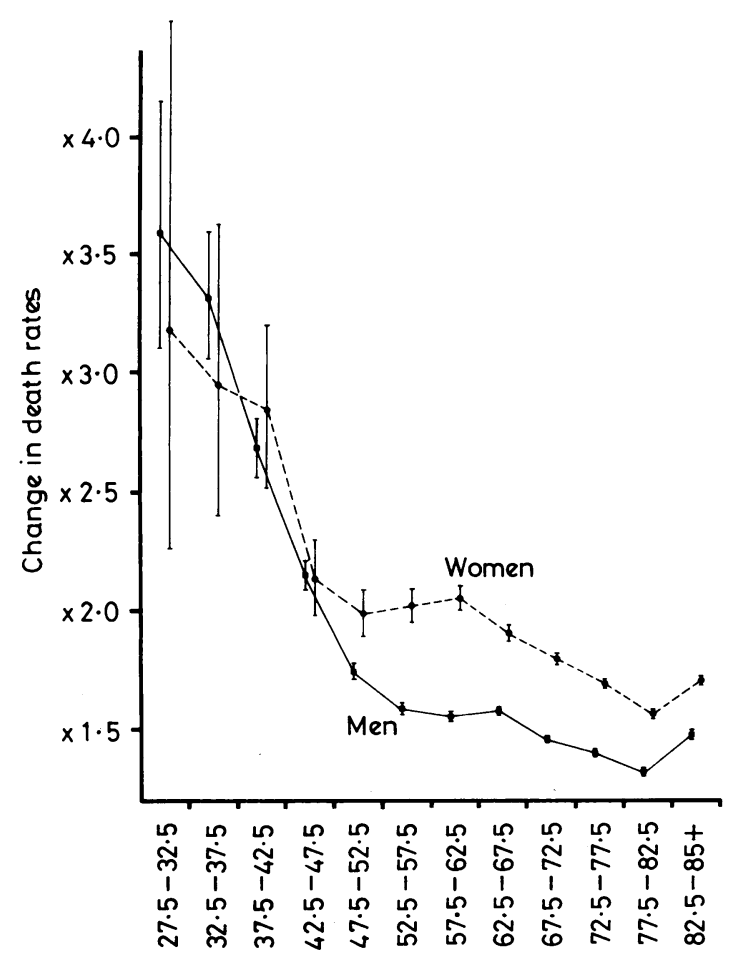

Consecutive 5-year age groups (midpoints)

FIG 2-Change in death rates from ischaemic heart disease between consecutive age groups of men and women (England and Wales 1970-4). Points are means \pm 2 SE.

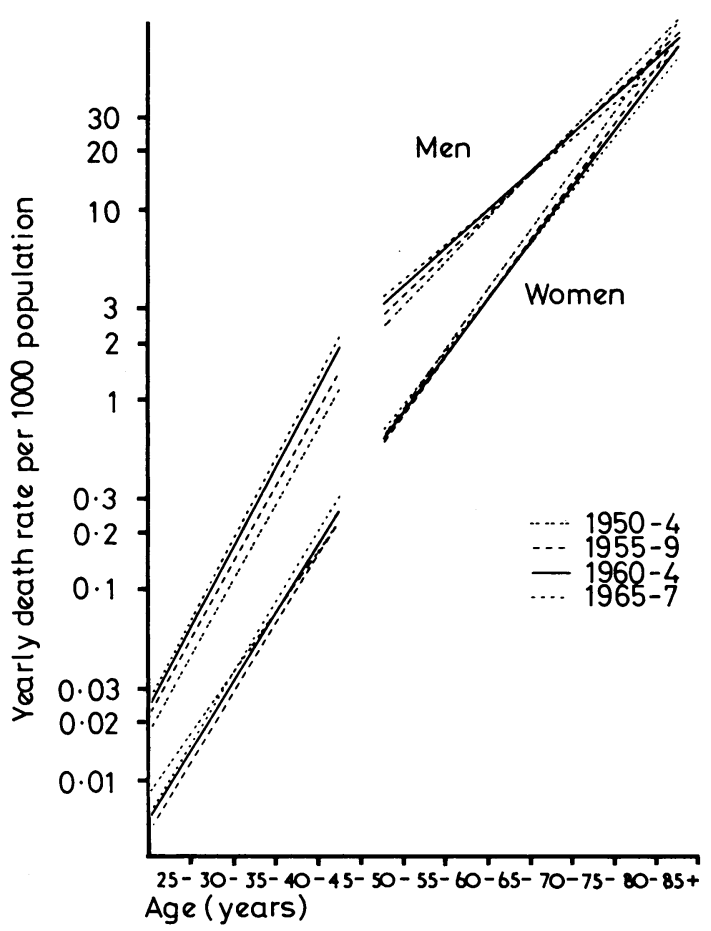

FIG 3-Death rates from arteriosclerotic and degenerative heart disease in men and women according to age (England and Wales 1950-67).

CHD deaths rates as they get older because the death rates in men increase more slowly after the age of 50 than before and more slowly thin the death rates in women.

Data for 1950-67 (CHD or ischaemic heart disease was classified as arteriosclerotic and degenerative heart disease, ICD 420-422, up to 1967) showed a similar pattern to those for 1970-4 (see figs 1 and 3). This trend, present in the UK for the past quarter of a century, also seems to be similar in other parts of the Western world, including the USA. ${ }^{3}$

\section{Discussion}

These observations suggest that at around the age of 50 men lose a factor that had previously put them at extra risk of developing CHD. The data do not support the idea that women lose protection from CHD after the menopause.

If male sex hormones put men at extra risk, this risk may diminish after the age of 50 , when plasma testosterone concentrations are reduced. ${ }^{45}$ The reduction occurs in total testosterone concentrations, particularly in the proportion of testosterone that is unbound to sex-hormone-binding globulin and which is thought to be the biologically active fraction. While there is a fall from the youngest to the oldest ages, a significant fall in unbound testosterone concentrations occurs only after the age of $50 . .^{5}$ In one study gonadotrophin concentrations were also measured, and the overall change from "young" to "old" was found to occur between 45 and 50 years. ${ }^{5}$

Testosterone seems to have little effect on total cholesterol concentrations, ${ }^{3}$ and the mechanism of any risk it might produce is not clear. Nevertheless, the idea of male sex hormones putting men at extra risk is more plausible than that of female sex hormones being protective, since large doses of oestrogen given to men for prostatic cancer and the use of oral contraceptives containing oestrogen and progesterone have both been shown to increase the risk of death from CHD. ${ }^{6}$ ?

We hope that these findings will lead to further studies on the role of male sex hormones in the aetiology of CHD. Furthermore, the idea that female sex hormones protect against $\mathrm{CHD}^{8}$ should probably be abandoned.

We thank Mr Michael Goddard, of the department of medical 
statistics and epidemiology at the London School of Hygiene and Tropical Medicine, for his advice on statistics.

\section{References}

1 Office of Population Censuses and Surveys, Mortality Statistics 1974 (Causes), DH2 No 1. London, HMSO, 1977.

2 Gray, R H, in The Menopause: $A$ Guide to Current Research and Practice, ed R J Beard, p 27. Lancaster, MTP Press, 1976.
${ }^{3}$ Furman, R H, Annals of the New $\cdot$ York Academy of Sciences, 1968, 149, 822.

4 Vermeulen, A, Rubens, R, and Verdonck, L, fournal of Clinical Endocrinology, 1972, 34, 730 .

${ }^{5}$ Stearns, E G, et al, American fournal of Medicine, 1974, 57, 761.

${ }^{6}$ Veterans Administration Co-Operative Urological Research Group, Surgery, Gynecology and Obstetrics, 1967, 124, 1011.

${ }^{7}$ Mann, J I, et al, British Medical fournal, 1975, 2, 241.

${ }^{8}$ British Medical fournal, 1977, 1, 862.

(Accepted 8 December 1977)

\title{
One drug for epilepsy
}

\author{
S D SHORVON, D CHADWICK, A W GALBRAITH, E H REYNOLDS
}

British Medical fournal, 1978, 1, 474-476

\section{Summary and conclusions}

We performed prospective trials of phenytoin and carbamazepine, assisted by blood level monitoring, in untreated patients newly referred with grand mal or partial seizures, or both, to a neurological clinic. At the time of follow-up (mean 28.5 months for phenytoin; 12 months for carbamazepine) $\mathbf{7 6 - 8 8} \%$ of patients were completely controlled. Twelve per cent of the patients on each drug had further seizures, despite an optimum blood level. When the blood drug concentration was in the optimum range there was a $98 \%$ reduction in grand mal attack rate and $\mathbf{9 2 - 9 3} \%$ reduction in partial seizure rate.

These results suggest that polypharmacy is largely, and possibly totally, unnecessary in newly diagnosed adult epileptics.

\section{Introduction}

Epileptic patients are usually treated with several drugs. A survey conducted in four European countries showed that each patient received an average of 3.2 drugs, of which $84.3 \%$ were anticonvulsants. ${ }^{1}$. This polypharmacy is unsatisfactory because (a) it increases the risks of chronic toxicity, ${ }^{2}(b)$ with the availability of blood level monitoring any individual anticonvulsant can now be used more effectively, ${ }^{3-5}$ and $(c)$ we are unaware of any satisfactory evidence that two (or more) drugs are more effective than one, used efficiently, in controlling any type of seizure.

In a retrospective survey ${ }^{6}$ of 50 chronic epileptics who were attending a neurological clinic and who were each taking two anticonvulsants we found that seizure control was improved in only $36 \%$ of patients in the six months after the addition of the second drug. It is questionable whether this rate of improvement is significantly better than that which would be produced by giving a placebo. Furthermore, when serum concentrations of the two drugs were subsequently measured we found a signifi-

University Department of Neurology, Institute of Psychiatry and King's College Hospital Medical School, London SE5

S D SHORVON, MA, MRCP, honorary registrar

D CHADWICK, BM, MRCP, honorary registrar

A W GALBRAITH, MA, MB, clinical assistant

E H REYNOLDS, MD, MRCP, consultant neurologist cant correlation between improved control and optimum levels of at least one drug.

We have already described ${ }^{5}$ a prospective study of 31 untreated outpatients with grand mal or partial seizures, or both, $\subseteq$ who were treated initially with phenytoin with the guidance of blood level monitoring. After a mean follow-up of 14.7 months only $10 \%$ of these patients needed a second drug because of continuing seizures despite an optimum blood level. We have followed up 26 of these patients for a mean of 28.5 months and have performed a similar study with carbamazepine in a further 25 patients, who have been followed for a mean of one year. We report here our findings.

\section{Patients and methods}

We studied consecutive patients (table I) referred to the neurology clinic, King's College Hospital, who (a) had a history of two or more recent tonic-clonic seizures or sufficient partial seizures to warrant treatment; $(b)$ had had no anticonvulsant treatment; and $(c)$ had no progressive neurological disease.

TABLE I-Details of patients in both prospective trials

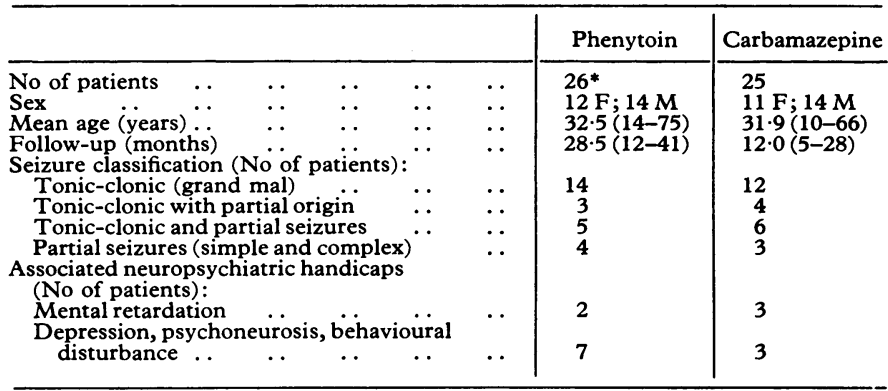

* Of the original 31 patients, one was excluded when a cerebral tumour (glioma) was discovered and four were lost to follow-up.

Each patient was treated initially with phenytoin $200-300 \mathrm{mg} /$ day or carbamazepine $200-400 \mathrm{mg} /$ day in two divided doses. Serum concentrations were measured at each outpatient visit (between 1000 am and 12 noon), which took place every two weeks to three months, depending on clinical progress. Patients and relatives were asked to record carefully any seizures and this information was documented at each outpatient visit. If seizures continued the dose of the drug was increased if necessary to obtain an optimum serum concentration. Only if seizures continued in spite of an optimum level was a second drug or placebo added and single drug treatment considered to have failed. The optimum ranges used were: phenytoin $10-20 \mathrm{mg} / 1$, and carbamazepine $4-8 \mathrm{mg} / \mathrm{l}$.

Serum phenytoin was measured by the gas chromatographic 